\title{
Development and Performance Study of Controlled Atmosphere for Fresh Tomato
}

\author{
Md. Farid Ahmed1*, Md. Zahirul Islam1, Md. Sazzat Hossain Sarker1', S. M. Kamrul Hasan', \\ Rakib Mizan² \\ ${ }^{1}$ Department of Food Engineering and Technology, Hajee Mohammad Danesh Science and Technology \\ University, Dinajpur, Bangladesh \\ ${ }^{2}$ Department of Food Processing and Preservation, Hajee Mohammad Danesh Science and Technology \\ University, Dinajpur, Bangladesh \\ Email: "farid_hstu05@yahoo.com
}

Received 17 January 2016; accepted 3 May 2016; published 6 May 2016

Copyright (C) 2016 by authors and Scientific Research Publishing Inc.

This work is licensed under the Creative Commons Attribution International License (CC BY).

http://creativecommons.org/licenses/by/4.0/

(c) $\underset{\mathrm{EY}}{\mathrm{B}}$ Open Access

\begin{abstract}
Development of a controlled atmosphere (CA) plant and shelf-life of fresh tomatoes at different storage conditions were studied in this research. The controlled chamber $\left(4.5^{\prime} \times 4.5^{\prime} \times 4.5^{\prime}\right)$ with supplement of $1 \% \mathrm{~L}$-ascorbic acid as antioxidant source was constructed using locally available materials. Fresh tomatoes were kept with wrapping by low density polyethylene under refrigerated and CA storage conditions. The maximum shelf-life of fresh tomato was 42 days under CA condition and followed by 35 days in refrigeration condition. Though initial cost of controlled atmosphere was high but it resulted in maximum shelf life of tomato. However, CA condition retained the physiological changes namely, color change, TSS, and weight loss of fresh tomatoes than that of stored in refrigerated condition. From nutritional point of view, it was concluded that developed CA plant could be used to extend the shelf-life of fresh tomatoes with minimum physicochemical changes throughout the storage period.
\end{abstract}

\section{Keywords}

Controlled Atmosphere, Tomato, Shelf-Life, Storage Study, Weight Loss

\section{Introduction}

Tomato is one of the most freshly consumed climacteric fruits, playing significant role in human nutrition for its vitamins, minerals, lycopene, $\beta$-Carotene and other bioactive constituents [1] [2]. Tomatoes are largely grown in

\footnotetext{
"Corresponding author.
}

How to cite this paper: Ahmed, M.F., Islam, M.Z., Sarker, M.S.H., Hasan, S.M.K. and Mizan, R. (2016) Development and Performance Study of Controlled Atmosphere for Fresh Tomato. World Journal of Engineering and Technology, 4, 168-175. 
winter season but summer variety tomato is newly developed variety in Bangladesh. This climacteric fruit is rich source of lycopene, which plays against freeradicals and different types of cancer [3]. In Bangladesh, tomatoes are consumed most in salad, sauce, pickles, chantey and other products. Usually, tomato is harvested at fully mature stage. Being climacteric fruit, tomato possesses short shelf-life, usually $8-12$ days. Fruit quality attributes mainly size, shape, color and firmness greatly influence consumers acceptance during this short life span.

Post-harvest loss of climacteric fruits and vegetables is directly related to post-harvest operations. Again, mechanical damage, inadequate storage system, rough handling and improper transportation system are also associated with post-harvest loss of fresh fruits [4]. On the other hand, physiological changes in tomato such as discoloration, alteration of respiratory metabolism, change in flavor and softening of texture affect the quality of fresh tomato during post-harvest operations [5]-[8].

Several studies have been carried out to extend the shelf-life of tomato including use of permitted chemicals, inhibition or slowdown of respiration by low temperature, modified or controlled atmosphere [9]. The effects of using chemicals as post-harvest treatment on human health are still unknown. Controlled atmosphere (CA) is found to be effective in hindering the ethylene production, activities of enzyme and lowering ripening process as well as senescence of climacteric fruits [10] [11]. Most of fresh horticultural products are found to respond favorably to controlled atmosphere in extending the shelf-life with nutritional quality [12]. CA storage system does not affect the antioxidant activity of apple differently from storage in ambient condition [13]. For storing avocado fruit in controlled atmosphere, no effects of CA storage on human health are reported in an earlier study [14].

Estimation says that postharvest loss of tomato in developing countries is almost $20 \%-25 \%$ [7]. Lack of storage facility is prime reason behind the spoilage of huge amount of fresh tomato in Bangladesh. Therefore, a large amount of tomato is found to be sold at cheap rate during peak season. Reduction of postharvest loss and extension of shelf-life of tomato are necessary to recover the grower's cost. If it is possible to supply any economic and easy preservation method to the growers, it will minimize the losses of tomatoes besides with contributing to the national GDP. Moreover, controlled atmosphere can be best option in this case. Even, farmers are not familiar with controlled atmosphere in Bangladesh but it can be easily developed using local raw materials. Locally developed controlled atmosphere can be effectively used for preserving small or large scale agricultural produces.

However, there is no research work regarding controlled atmosphere for storage of fresh tomato in Bangladesh. This research work was designed to study the storage performance of tomatoes stored at different conditions and develop an economical controlled atmosphere storage system for tomato.

\section{Materials and Methods}

\subsection{Design of Controlled Atmosphere Plant}

\subsubsection{Storage Chamber}

The dimensions of the storage chamber were selected $4.5 \times 4.5 \times 4.5 \mathrm{ft}$ by making similarities with the experiment of CA storage for bananas [15]. The storage chamber was firstly structured by 1.5 inch PVC pipe and joints. Then polyethylene film of $140 \mathrm{gsm}$ and $5 \mathrm{ft}$ roll width was used for constructing the wall of the storage chamber (Figure 1(a)).

\subsubsection{Air Purifier Chamber}

The air purifier chamber was made by timber $\left(2^{\prime} \times 1^{\prime \prime} \times 2^{\prime}\right)$ having dimensions $2 \times 2 \times 2 \mathrm{ft}$. This dimension was fixed with respect to storage chamber. The two chambers were joined by PVC pipe of 6 inch dia. And two fans of dia. 12" and 8" were also used at both the inlet and outlet sides of the storage chamber (Figure 1(a)).

\subsection{Operating the Controlled Atmosphere}

The basic principle of preservation of fresh fruits and vegetables in the CA is maintaining higher the amount $\mathrm{CO}_{2}$ and lower amount $\mathrm{O}_{2}$ than normal composition of air. Optimum storage temperature and $\mathrm{RH}$ for the desired product were also maintained. For the sake of above operating principle, an air flow of $1-1.5 \mathrm{cfm} / \mathrm{min} / \mathrm{btu}$ should be maintained and the chemicals or such arrangement is required for purifying the circulating air and also closed it for leak proof (Figure 1(b)). 


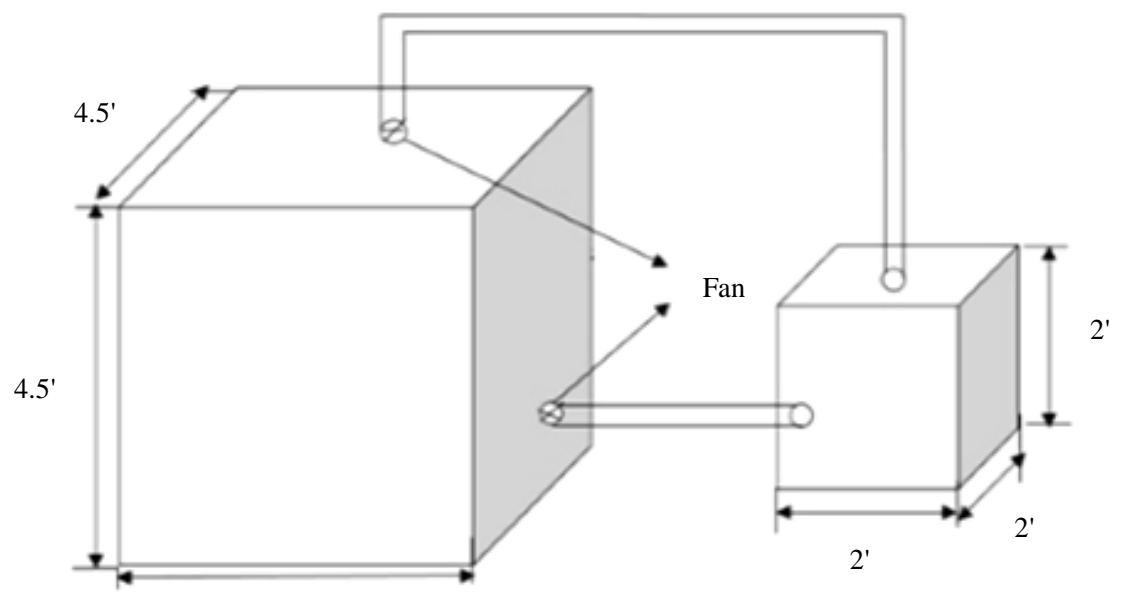

$4.5^{\prime}$

(a)

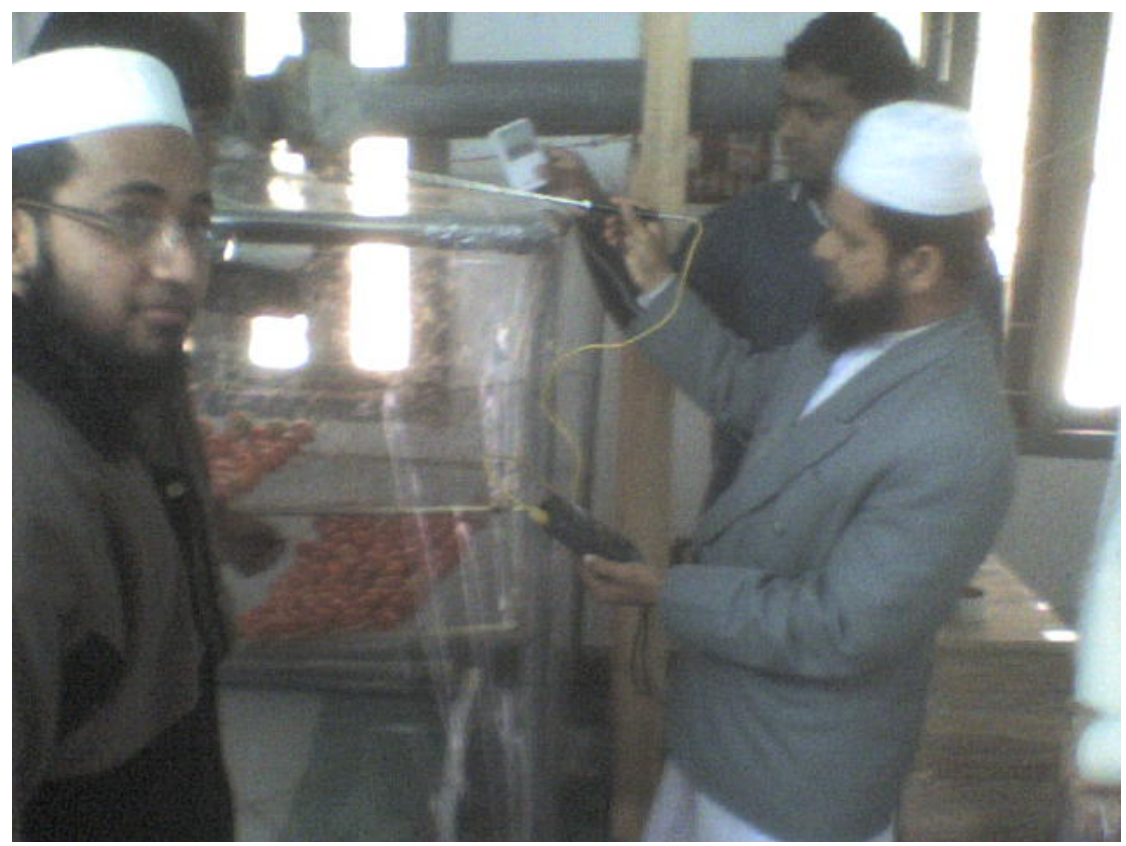

(b)

Figure 1. (a) Controlled atmosphere plant; (b) Fresh tomato in developed controlled atmosphere plant.

\subsection{Sample Collection}

Fresh and fully mature tomatoes were harvested manually from the research field of Hajee Mohammad Danesh Science and Technology University, Dinajpur. Harvested tomatoes were then sorted out to get almost similar tomatoes for further use as raw material in this research.

\subsection{Storage of Tomato under Different Conditions}

Sorted tomatoes were stored in two different storage conditions namely, refrigeration and controlled atmosphere condition. In refrigerated condition, tomatoes were weighed and kept in the refrigerator with low density polyethylene bags. In controlled atmosphere plant, tomatoes were kept at temperature of $20^{\circ} \mathrm{C}$ with $\mathrm{RH}$ of $75 \%-80 \%$. Antioxidant in the rate of $1 \%$ of product weight was applied in the wooden chamber in perforated bag and the air flow was maintained $1-1.5 \mathrm{cfm} / \mathrm{min} /$ Btu. 


\subsection{Physico-Chemical Analysis}

Degree of maturity was measured with color change where color was measured by comparing with color chart and scored them with numeric value. Weight loss of tomato was calculated by differences between initial weight and final weight divided by initial weight at three days interval of storage period. Total soluble solids of tomato was measured using refractometer according to standard method of AOAC [16]. The $\mathrm{pH}$ of tomatoes was determined using $\mathrm{pH}$ meter according to method of Rangana [17].

\subsection{Statistical Analysis}

Obtained data from physico-chemical analysis were statistically analyzed by one way ANOVA using SPSS program (version 20). DMRT was applied to differentiate the mean value significantly with a significance level of $5 \%$.

\section{Results and Discussion}

The shelf life of tomatoes varied under different storage conditions. The higher shelf life of tomatoes was observed as 42 days under controlled atmosphere condition and followed by 35 days of storage life at refrigeration condition.

\subsection{Degree of Maturity}

Degree of maturity relates to bio-chemical process of living cells. Regarding fresh horticultural products, degree of maturity would be increased with the storage period. Degree of maturity of stored tomato was expressed in numeric value and presented in Figure 2.

As expected, higher degree of maturity was observed in stored tomatoes in both of storage conditions. Before third week of storage, degree of maturity in refrigeration condition was lower than controlled atmosphere but at the end of storage period, it was slightly higher than observed in controlled atmosphere (Figure 2).

\subsection{Degree of Color}

In storage study, degree of color is one of the important quality parameters. Color development of fruits depends on the ethylene production and ethylene production largely depends on storage condition. Color development of tomatoes in terms of numeric value in two different storage conditions is shown in Figure 3. Color development of tomato stored in refrigeration condition was not observed in first week of storage and it started in second week but rate was lower than observed in controlled atmosphere. However, same rate of color development was observed under both of storage conditions in third week of storage period. Finally, lower color development in tomato was observed in controlled condition at the end of storage condition (Figure 3).

\subsection{Total Soluble Solids}

Change in total soluble solids content in tomatoes stored in two different conditions are shown in Figure 4 .

It was found that TSS increased in both of storage conditions. Data revealed that there was no significant ( $\mathrm{p}>$ 0.05 ) difference in TSS content in tomatoes stored in both of two conditions up to 21 days of storage. At last two weeks of storage period, TSS increased significantly $(\mathrm{p}<0.05)$ in tomatoes stored in refrigeration condition than stored in modified condition. This result was in agreement with the findings of Znidarcic et al. [18] who also reported increased soluble solids content in tomato stored in refrigeration condition. Degradation of polysaccharide was reported as possible reason of increasing soluble solids content in fruits with the increase of maturity [19]. However, from the view of storage quality, developed controlled atmosphere plat retained the ripening process of tomato effectively in this study.

\section{4. $\mathrm{pH}$}

Change in $\mathrm{pH}$ value in stored tomatoes is shown in Figure 5. As seen in Figure 5, pH value decreased in both of storage conditions during the first seven days of storage. After first week of storage, $\mathrm{pH}$ value was found to be increased in stored tomatoes under both of two conditions. Significant $(\mathrm{p}<0.05)$ difference in $\mathrm{pH}$ value in 


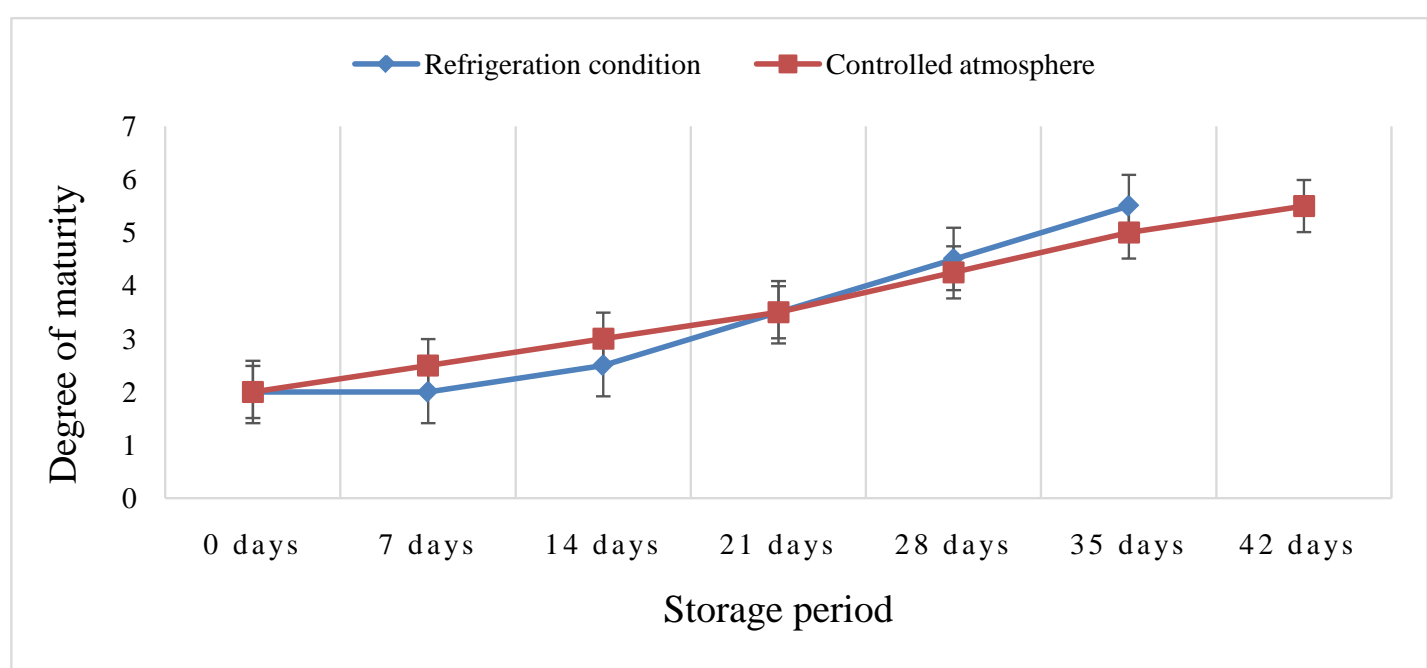

Figure 2. Change in maturity in stored tomatoes.

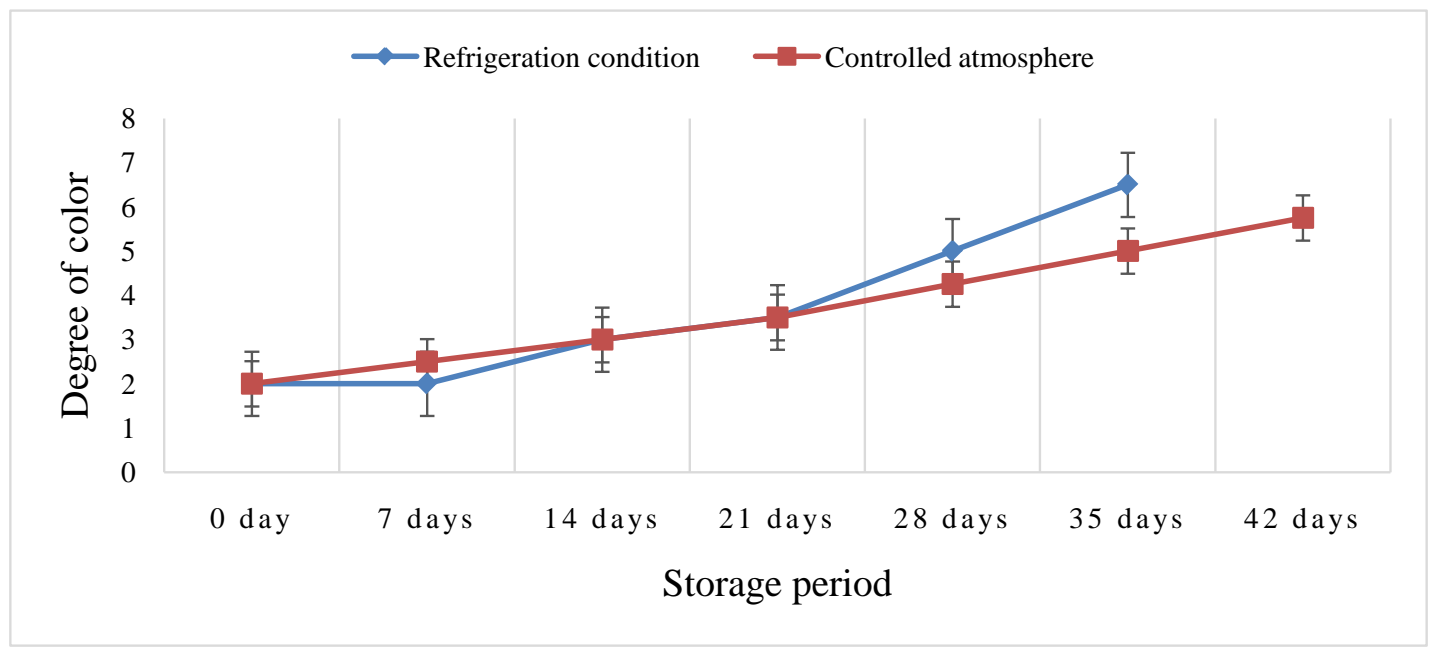

Figure 3. Color development in stored tomatoes.

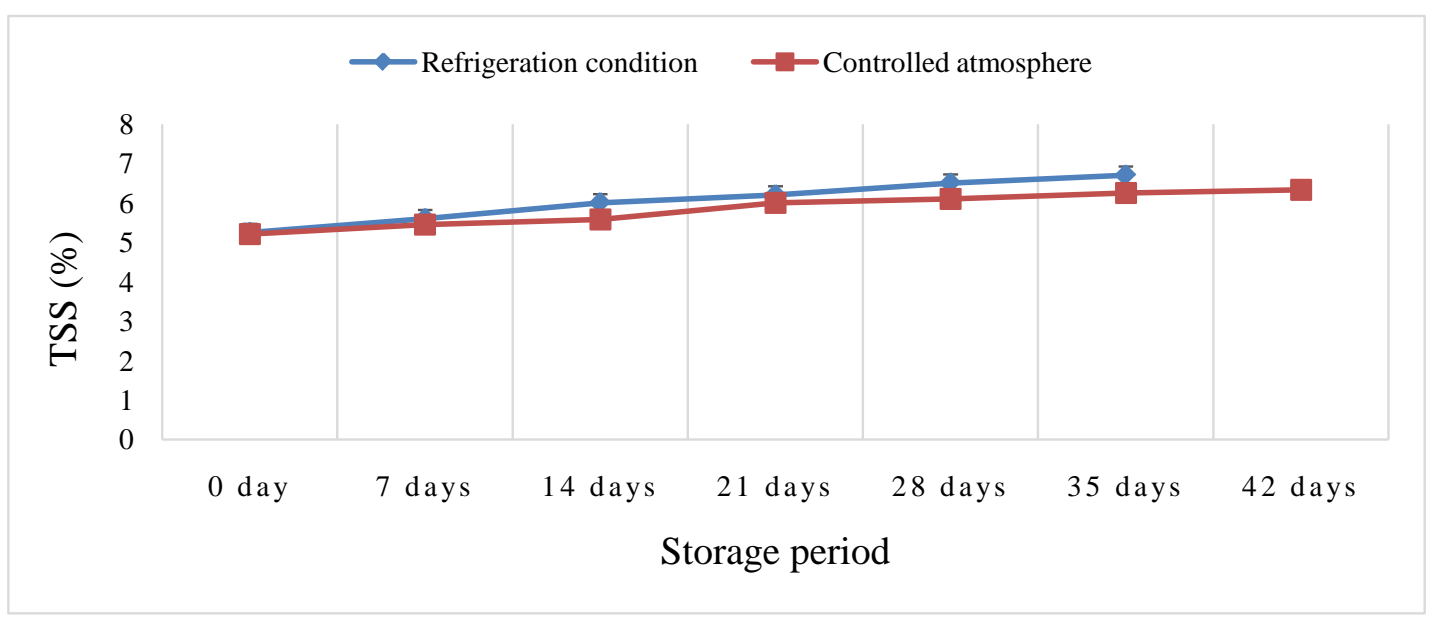

Figure 4. Change in total soluble solids in stored tomatoes. 


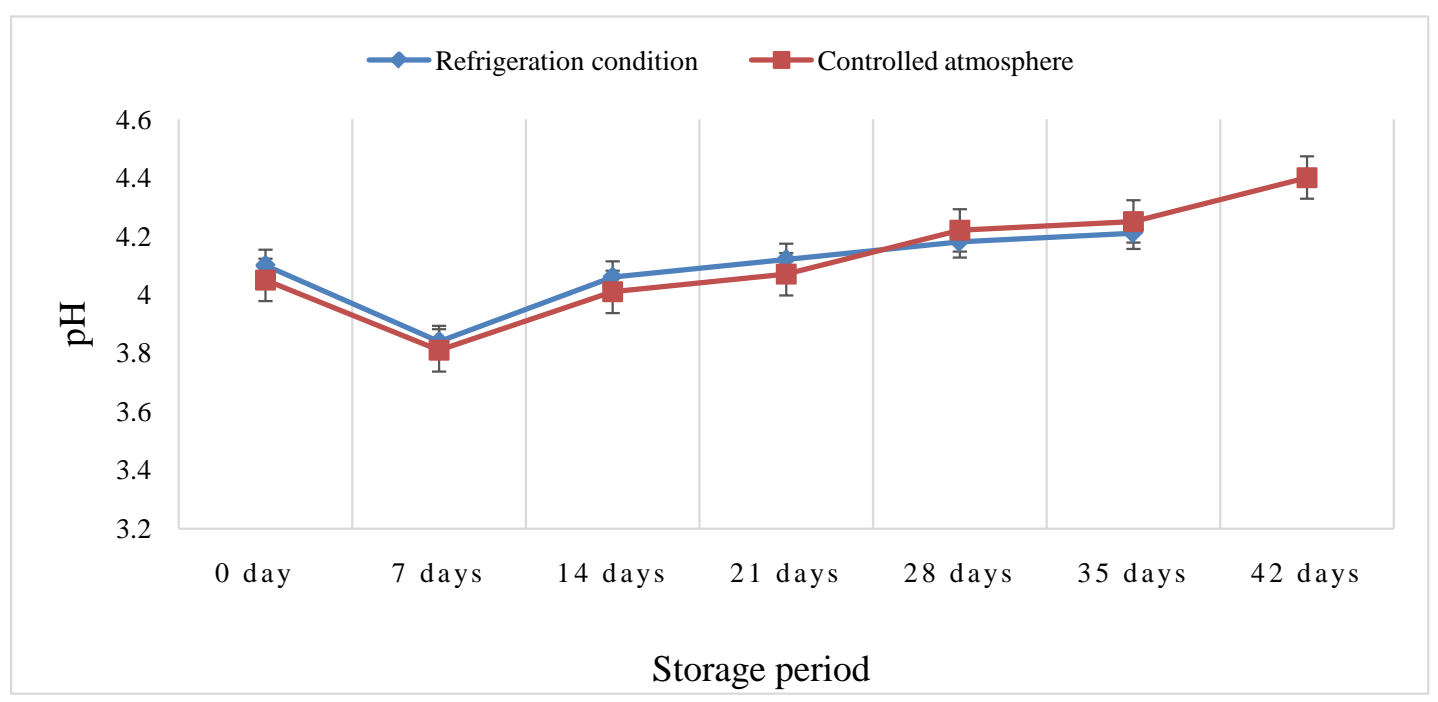

Figure 5. Change in $\mathrm{pH}$ in stored tomatoes.

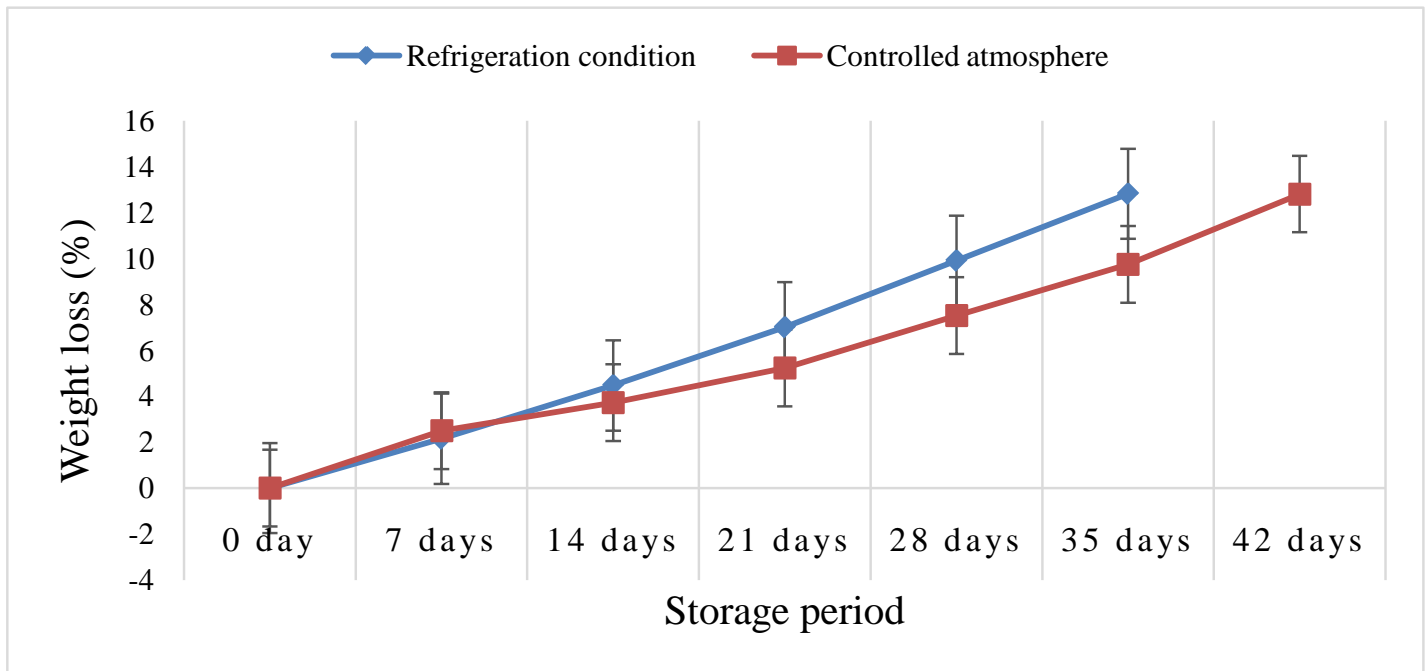

Figure 6. Weight loss of stored tomatoes.

stored tomatoes under both of conditions was not observed during the 35 days of storage study. However, $\mathrm{pH}$ increased at a higher rate in stored tomatoes under controlled atmosphere during the last week of storage study. This result was in line with the findings of Castro et al. [20] who reported that $\mathrm{pH}$ increased with the increase of degree of maturity.

\subsection{Weight Loss}

Weight loss during storage is directly related to storage temperature and period. It is resulted because of moisture loss through transpiration. However, weight loss of fresh tomato during storage period was found almost linear under both of storage conditions (Figure 6). The rate of weight loss was higher in controlled atmosphere during first week of storage period than refrigeration condition. From second week of storage period, weight loss was observed to be faster in refrigeration condition compared to controlled atmosphere. At the end of 35 days of storage, tomato stored in refrigeration experienced $12.81 \%$ weight loss, whereas weight loss of $9.74 \%$ was recorded in controlled atmosphere. In addition, weight loss of $12.8 \%$ was observed in controlled atmosphere after 42 days of storage study. According to Znidarcic et al. [19], weight loss of 18.7\% was observed in tomatoes stored in $10^{\circ} \mathrm{C}$ for 28 days. 


\section{Summary and Conclusion}

Shelf-life of fresh tomatoes could be extended in refrigeration condition, but only lowering the temperature was not very much effective to maintain storage quality. Under refrigeration condition, continuous biosynthesis process due to high amount of oxygen level caused conversion of polysaccharides, which resulted in increasing amount of TSS and softening of tomatoes.

One of most important outcomes of this research that locally developed controlled atmosphere (CA) plant using cheap construction materials and L-ascorbic acid as an oxygen inhibitor was effective storage condition to extend the shelf-life of fresh tomatoes. Nevertheless, it could be suggested that if it was possible to maintain $1 \%$ antioxidant of tomato weight, $85 \%-90 \% \mathrm{RH}$ at storage temperature $18^{\circ} \mathrm{C}-20^{\circ} \mathrm{C}$ or below but not less than $10^{\circ} \mathrm{C}$ in CA, it would increase the shelf life 2 to 3 times more than current result. Therefore, controlled atmosphere could be introduced for increasing the shelf-life with minimum physiological changes and weight loss than normal atmosphere as well as refrigeration condition.

\section{References}

[1] Simonne, A.H., Behe, B.K. and Marshall, M.M. (2006) Consumers Prefer Low-Priced and High-Lycopene-Content Fresh-Market Tomatoes. HortTechnology, 16, 674-681.

[2] Toor, R.K. and Savage, G.P. (2006) Changes in Major Antioxidant Components of Tomatoes during Post-Harvest Storage. Food Chemistry, 99, 724-727. http://dx.doi.org/10.1016/j.foodchem.2005.08.049

[3] Giovanucci, I.L., Ashcerio, A., Rimm, E.B., Stampfer, M.M., Colditz, G.A. and Willett, J. (1995) Intake of Carotenoids and Retinol in Relation to Risk of Prostate Cancer. National Cancer Institute, 87, 1767.

[4] CEAGESP (2000) Classificação de tomate. Programa Horti \& Fruti, São Paulo.

[5] Galvis-Vanegas, J.A. (1987) Fisiologia pós-colheita de tomate (Lycopersicon esculentum Mill) cultivar Ângela. UNICAMP, FEA, Campinas.

[6] Jackman, R.L., Marangoni, A.G. and Stanley, D.W. (1990) Measurement of Tomato Fruit Firmness. HortScience, 25, 781-783.

[7] Kader, A.A. (1992) Postharvest Technology of Horticultural Crops. 2nd Edition, Univ. Calif., Div. of Agr. and Nat. Resources, Publ, Vol. 3311, 296.

[8] Moretti, C.L. and Sargent, S.A. (2000) Alteração de sabor e aroma em tomates causado por impacto. Scientia Agricola, 57, 385-388. http://dx.doi.org/10.1590/S0103-90162000000300002

[9] Kalt, W., Forney, C.F., Martin, A. and Prior, R.L. (1999) Antioxidant Capacity, Vitamin C, Phenolic, and Anthocyanin after Fresh Storage of Small Fruits. Journal of Agricultural and Food Chemistry, 47, 4638-4644. http://dx.doi.org/10.1021/jf990266t

[10] Kader, A.A. (1986) Biochemical and Physiological Basis for Effects of Controlled and Modified Atmospheres on Fruits and Vegetables. Food Technology, 40, 99-104.

[11] Calderon, M. and Barkai-Golan, R. (1990) Food Preservation by Modified Atmospheres. CRC Press, Boca Raton.

[12] Blanpied, G.D., Bartsch, J.A. and Hicks, J.R. (1993) Proceedings from the Sixth International Controlled Atmosphere Research Conference. Northern Regional Agr. Eng. Ser., Ithaca, New York, 887.

[13] Van Der Sluis, A.A., Dekker, M., De Jager, A. and Jongen, W.M.F. (2001) Activity and Concentration of Polyphenolic Antioxidants in Apple: Effect of Cultivar, Harvest Year, and Storage Conditions. Journal of Agricultural and Food Chemistry, 49, 3606-3613. http://dx.doi.org/10.1021/jf001493u

[14] Meyer, M.D., Landahl, S., Donetti, M. and Terry, L.A. (2011) Avocado. In: Terry, L.A., Ed., Health-Promoting Properties of Fruit and Vegetables, CAB International, Oxford, 27-50. http://dx.doi.org/10.1079/9781845935283.0027

[15] Shorter, A.J. (1987) Controlled Atmosphere Storage of Bananas in Bunches at Ambient Temperature. CSIRO Food Research Quarterly, 47, 61-63.

[16] AOAC (1995) International Official Methods of Analysis. 18th Edition, Association of Official Analytical Chemists, Washington.

[17] Rangana (1979) Manual Analysis of Fruits and Vegetables Product. Tata McGraw Hill Co. Ltd., New Delhi.

[18] Znidarcic, D., Ban, D., Oplanic, M., Karic, L. and Pozrl, T. (2010) Influence of Postharvest Temperatures on Physicochemical Quality of Tomatoes (Lycopersicon esculentum Mill). Journal of Food, Agriculture \& Environment, 8, 21-25.

[19] Salunkhe, D.K., Jadhar, S.J. and Yu, M.H. (1974) Quality and Nutritional Composition of Tomato Fruits Influenced by Certain Biochemical and Physiological Changes. Qualitas Plantarum, 24, 85-113. 
http://dx.doi.org/10.1007/BF01092727

[20] Castro, L.R., Vigneault, C., Charles, M.T. and Cortez, L.A.B. (2005) Effect of Cooling Delay and Cold-Chain Breakage on "Santa Clara" Tomato. Journal of Food, Agriculture and Environment, 3, 49-54. 